\title{
Treatment of Kaposi sarcoma-associated herpesvirus-associated cancers
}

\author{
Dirk P. Dittmer ${ }^{1,2}$, Kristy L. Richards ${ }^{1,3}$ and Blossom Damania ${ }^{1,2}$ * \\ 1 Program in Global Oncology, Lineberger Comprehensive Cancer Center, University of North Carolina at Chapel Hill, Chapel Hill, NC, USA \\ ${ }^{2}$ Department of Microbiology and Immunology, University of North Carolina at Chapel Hill, Chapel Hill, NC, USA \\ ${ }^{3}$ Division of Hematology/Oncology, Department of Medicine, University of North Carolina at Chapel Hill, Chapel Hill, NC, USA
}

\section{Edited by:}

Keiji Ueda, Osaka University Graduate

School of Medicine, Japan

\section{Reviewed by:}

Chris Sullivan, University of Texas at

Austin, USA

Keiji Ueda, Osaka University Graduate

School of Medicine, Japan

*Correspondence:

Blossom Damania, Lineberger

Comprehensive Cancer Center,

University of North Carolina at Chapel

Hill, CB\#7295, Chapel Hill, NC 27599,

USA.

e-mail:damania@med.unc.edu
Kaposi sarcoma (KS) is the most frequent AIDS-defining cancer worldwide. KS-associated herpesvirus (KSHV) is the etiological agent of $\mathrm{KS}$, and the virus is also associated with two lymphoproliferative diseases. Both KS and KSHV-associated lymphomas, are cancers of unique molecular composition. They represent a challenge for cancer treatment and an opportunity to identify new mechanisms of transformation. Here, we review the current clinical insights into KSHV-associated cancers and discuss scientific insights into the pathobiology of KS, primary effusion lymphoma, and multicentric Castleman's disease.

\section{Keywords: KSHV, lymphoma, sarcoma, viral cancer, therapy}

\section{KAPOSI SARCOMA}

Kaposi sarcoma (KS) is an endothelial cell lineage tumor that is caused by KS-associated herpesvirus (KSHV). Clinically, multiple manifestations of KS have been observed. It is unclear whether these different clinical forms have the same molecular make-up and whether they would respond to the same treatment. The clinical forms of KS are classic KS, endemic KS, transplant-associated KS, and AIDS-associated KS. In the era of effective antiretroviral therapy (ART), we now also encounter a new type of KS that is HIV associated, but no longer AIDS-defining as it appears in individuals with near-normal CD4 counts.

Classic KS was described by M. Kaposi. He identified five patients exhibiting hemorrhagic sarcoma of the skin as well as sarcoma of internal organs upon postmortem examination (Kaposi, 1872; Abada et al., 2008). Note that Kaposi described an aggressive tumor in older - HIV-negative - men, whereas to date the classic form of KS is considered to be an indolent disease restricted to the skin. It also predominantly occurs in older men of Mediterranean and Eastern European origin. One report suggests a hereditary component for classic KS (Guttman-Yassky et al., 2004).

Endemic KS was described as occurring in sub-Saharan Africa before the emergence of HIV (Maclean, 1963). African KS is histologically indistinguishable from other forms of KS. It tends to be aggressive, and it is regularly seen in children (Slavin et al., 1970). Endemic KS is the leading cancer of children in some African countries owing to near universal infection with KSHV and other yet to be identified co-factors. It is as frequent, and as characteristic for the "Malaria belt" as Epstein-Barr-Virus (EBV)-associated endemic Burkitt lymphoma (BL). The only treatment, if available, is radiation and/or cytotoxic chemotherapy. In severe cases of KS that are localized to the limbs amputation is indicated.
Transplant-associated KS is seen in KSHV seropositive patients receiving immunosuppressive agents. Thus the incidence rates of transplant-associated KS track the seroprevalences of KSHV. Transplant-associated KS is a significant cause of morbidity and mortality in Italy, Turkey, Saudia-Arabia, e.g., in developed countries with substantial KSHV seroprevalence (8-18\%). KS seen in solid organ transplant recipients is called iatrogenic KS (Harwood et al., 1979). The first-line therapy is tapering of the immune suppressive regimen. This often leads to lesions resolution (or immune-mediated tumor regression), though it risks organ rejection. Lately, rapamycin has emerged as an effective therapy for transplant-associated KS (Stallone et al., 2005), either as second-line substitutive immune suppressive regimen or as addition to cyclosporine mediated immune maintenance regimens. Transplant-associated KS tends to occur later (after the first year) than viremic herpesvirus-associated complications. Either the donor organ or the recipient can be the source of KSHV in this setting, as well as de novo exposure post transplantation when immunosuppressive therapies are administered (Barozzi et al., 2003).

AIDS-KS is found with greatly increased frequency in HIVpositive men. It is an AIDS-defining disease and was initially called epidemic KS. Note that KS can become an epidemic disease only in those HIV-positive populations that have high prevalence rates of KSHV. In the US and other developing countries, these are men who have sex with men, not individuals who acquired HIV through blood transfusion prior to the introduction of mandatory HIV screening of blood supplies (Gao et al., 1996a,b; Kedes et al., 1996). In regions of endemic KS, where initial exposure happens during childhood, these are all individuals - children, men, and women (though even here KS is twice as frequent in men as in women). In the context of substantial immune suppression, i.e., terminal AIDS, 
KS can be highly aggressive, and spreads quickly to internal organs (Gottlieb et al., 1981). The clinical presentation of AIDS-KS has become more diverse with the advent of ART. First, approximately $30 \%$ of HIV-associated KS cases in the US now occur in the setting of successfully ART-suppressed HIV viral load. These cases tend to have a milder clinical presentation (Maurer et al., 2007; Krown et al., 2008). Second, terminal AIDS-KS-associated with ART failure remains the leading malignancy of HIV-positive men. Third, KS is often still the first indication of HIV infection, particularly in Sub-Saharan Africa. Like transplant-associated KS the lesions often regress after immune-restoration post initiation of ART. Fourth, the opposite clinical scenario has also been seen: HIV-infected individuals who newly start ART develop KS within the first months of therapy, a manifestation that defines immune reconstitution inflammatory syndrome (IRIS; Connick et al., 2004; Bower et al., 2005; Crane et al., 2005; Leidner and Aboulafia, 2005).

How do we treat these different forms of KS? Is there a molecular mechanism or signature that may be utilized as the basis of rational therapy choice? And how do we measure KS responses to compare different therapeutic modalities? As mentioned above KS can be limited or can present as fulminant disease, with internal organ involvement. Persons with severe KS may also develop primary effusion lymphoma (PEL) or suffer from concurrent KSHVassociated multicentric Castleman disease (MCD; described in detail in later sections; see below). There is a wide range in clinical presentations. Cutaneous lesions tend to be most common at the lower extremities, but can appear anywhere (Cheung et al., 2005). Oral KS, concurrent with cutaneous KS or as a single lesion absent cutaneous involvement, has been reported in the context of HIV infection. Whereas cutaneous lesions are a cause of stigma as much as physical pain, the more insidious presentation is that of KS in internal organs (lung, liver) without overt extensive cutaneous involvement, as is seen, e.g., in some patient populations in Brazil (deSouza, personal communication).

Cutaneous KS lesions are typically dark and can present as patches, papules, plaques, or nodules. There is a suspicion that these clinical forms are part of a disease progression. However, the different forms can present simultaneously on a single individual. No formal studies have explicitly linked these broad descriptors to survival or to response to therapy. KS can affect all internal organs including but not limited to the lungs, liver, lymph nodes, and the gastrointestinal tract. KS presents with lymphedema quite frequently. As with many carcinomas, lymph node involvement signifies poor prognosis in children. In adults, lymph node involvement does not always portend the same poor prognosis as other cancers (Myskowski et al., 1988). The current staging system of AIDS-associated KS is based on the AIDS Clinical Trials Group (ACTG) Oncology Committee (Krown et al., 1989, 1997). Akin to the standard TNM staging for solid tumors (Sobin et al., 2009), it incorporates extent of tumor, where T0 signifies that the KS is restricted to the skin and/or lymph nodes and/or minimal oral disease (i.e., non-nodular KS confined to the palate), and T1 signifies tumor-associated edema or ulceration, gastrointestinal KS, extensive oral KS, or KS in other non-nodal internal organs. Other criteria in this classification include the severity of immunodeficiency (I0 or I1) as measured by CD4 count and various systemic symptoms/illnesses ( $\mathrm{S} 0$ or $\mathrm{S} 1$ ). Both poor immune response (I), as well as the stage of the tumor (T), most accurately predicted survival of AIDS-KS in the pre-ART era (Krown et al., 1997). Both tumor stage and systemic illness also predicts dismal prognosis in the post-ART era (Nasti et al., 2003). Of note this classification system was developed for AIDS-KS prior to ART. Whether this classification is also applicable to endemic KS is currently under study. Notably this classification does not consider KSHV viral load, as this classification system predates the discovery of KSHV. It does not consider molecular markers of the tumor, such as proliferative index of the lesions or circulating biomarkers, such as IL-6.

Regardless of clinical acumen, lesional biopsy is required to establish KS, as lesions can be mistaken for hemangiomas, dermatofibromas, hematomas, purpuras etc., and in developing countries, tuberculosis (skin and internal). Other diseases that may be mistaken for KS due to similar presentations include bacillary angiomatosis, lymphangioma, angiosarcoma, and hemangioendothelioma to list just a few.

Histologic diagnosis of KS is required prior to cytotoxic therapy. Most individuals with KS lesions will have detectable KSHV in blood and KS viral load is prognostic for KS. However, the degree of viremia is highly variable. A study of classic KS reported an average of $<100$ copies/ml (Guttman-Yassky et al., 2007), whereas AIDS-KS is almost always associated with $>1000$ copies $/ \mathrm{ml}$. Compared to other herpesvirus infections (Epstein-Barr-Virus or human Cytomegalovirus) in the setting of AIDS or transplantassociated immune suppression, the level of viremia is low, reducing the sensitivity of KSHV viral load based assays. By contrast specificity of KSHV viral load assays is high, as a high viral load is almost always associated with overt or imminent KS.

Seropositivity for KSHV latent nuclear antigen (LANA), which at present is the most specific assay, cannot be used to diagnose KS. It establishes exposure to the risk factor KSHV, however exposure precedes disease by a long time. A rise in serum antibody titers may happen in some instances, but not others, particularly in heavily immune deficient individuals. Early studies estimated a median latency of 7 years between exposure and disease for pre-ART AIDS-KS (Gao et al., 1996a). For classic KS, the latency may be even longer; for endemic KS in children the latency can be months.

The diagnosis of KS is based on histologic features of the H\&E stain. As of late, immunohistochemistry for the KSHV antigen, LANA, has been added to the diagnostic repertoire. As another alternative, KSHV detection by PCR for viral DNA or RNA may be informative. The problem here is that sensitivity of the PCR depends on the accuracy and location of the excisional biopsy; for instance, to minimize bleeding the most aggressive lesion is typically not biopsied. A confounding factor for RNA-based diagnosis has been the RNAse-rich environment of the lesions, which prevented RNA analyses by traditional methods (e.g., Northern blot) until the introduction of more sensitive methods such as quantitative real-time PCR (Renne, Lagunoff, Dittmer, unpublished).

Lesions are composed of vascular spaces comprised of large endothelial cells that protrude into the vessel lumen due to thinning of the blood vessel wall. Spindle cell proliferation can be sparse or significant. These proliferating spindle cells are the KS tumor cells and the target for anti-KS therapy. Sometimes the lesions resemble a fibrosarcoma. The presence of extravascular erythrocytes and narrow irregular, angulated slits is a classic hallmark 
of KS. Inflammatory mononuclear cell infiltrates are seen consistently and are generally comprised of infiltrating lymphocytes, macrophages, and plasma cells. Exactly how they contribute to lesion development (or if at all) is unclear.

\section{TREATMENT}

As there are many forms of KS, one must separately consider treatment options for each form. Clinical trial data in KS, especially phase III studies, are limited by declining numbers of patients in developed countries in the post-ART era. Therefore, published treatment recommendations are based on both older trial data, limited (phase I/II) trials, and consensus opinion. Of note, this review by no means offers specific recommendations. These fall into the purview of the treating physician. Rather, we will focus on those regimens for which a reasonable rational basis exists and these regimens are often arrived at post facto. With rare exceptions, phase III efficacy data are usually not available for the more modern therapies.

Kaposi sarcoma, as an AIDS-presenting manifestation in ART naïve patients, often responds to ART and the ensuing immune reconstitution alone. However, typically no more than half of patients achieve lesion resolution with successful ART (Nguyen et al., 2008). At present there are no clinical or molecular parameters that distinguish between responders and non-responders. A phase III clinical trial comparing ART alone, or with delayed chemotherapy to ART, with immediate adjunctive chemotherapy for limited AIDS-KS in resource-limited settings (REACT-KS) has recently started enrolling. Whether some ART regimens are better suited to treat AIDS-KS than others is also currently under investigation. Some HIV protease inhibitors have direct anti-tumor activity (Monini et al., 2004), and some also exhibit anti-viral KSHV activity (Gantt et al., 2011). Antiretroviral combinations with nonprotease-inhibitors can also induce KS regression (Bower et al., 2006).

Systemic chemotherapy, e.g., Doxil ${ }^{\mathrm{TM}}$, can be required in AIDS$\mathrm{KS}$ if lesions do not regress with primary ART therapy, and can be useful in other situations as well. KS as an indicator of ART failure requires second and/or third line therapy for HIV, again with concurrent or delayed chemotherapy. Early systemic chemotherapy may help to suppress IRIS-associated flares (Leidner and Aboulafia, 2005). KS that develops in the presence of successful ART also requires KS-targeted chemotherapy.

In addition to ART, radiotherapy or surgery can be used to treat isolated lesions. Cytotoxic chemotherapy includes vincristine, bleomycin, doxorubicin, and etoposide, as single agents or in combination. In particular the liposomal formulations of pegylated-doxorubicin (Doxil ${ }^{\mathrm{TM}}$ ) or daunorubicin have shown clinical efficacy and are often the first-line agent used. Taxol is considered as a second-line option. Its efficacy is, within a small margin, comparable to doxil. These chemotherapy options are part of the standard repertoire of cytotoxic therapy for solid tumors, including sarcomas, and were developed and clinically evaluated in the pre-ART and pre-KSHV era. Many of these drugs have significant toxicities and a lifetime limit of exposure. While these agents are efficacious, they were not chosen because of unique insights into the biology of the disease and they do not take into account any novel targets that the tumor-associated virus may present. Future improvements in KS treatment (i.e., higher efficacy and lower toxicity) will depend on better exploitation of these disease-specific targets.

In patients afflicted with transplant-associated KS, complete regression of cutaneous KS was seen when immunosuppressive therapy was switched from cyclosporin to rapamycin (Campistol et al., 2004; Stallone et al., 2005). These results have been recapitulated in immune deficient animal models of KS (Roy, Dittmer, unpublished observation), and similar encouraging response rates have been seen by others (Gutierrez-Dalmau et al., 2005; Zmonarski et al., 2005; Lebbe et al., 2006). Of course, exceptions have also been reported (Guenova et al., 2008). A recent study showed rapamycin (sirolimus) to be well tolerated over a long period of time (10 months) and to induce encouraging molecular responses and disease stabilization in a limited study of AIDS-KS (Krown et al., 2012).

Rapamycin is an allosteric inhibitor of mTORC1. Rapamycin binds to FK506-binding protein 12 (FKB12). The rapamycinFKB12 complex inhibits mammalian target of rapamycin (mTOR) kinase activity (Sabers et al., 1995). Rapamycin typically inhibits cell proliferation with IC50s of $0.5-5 \mu \mathrm{M}$. Rapamycin is established clinically since 1999 as a second-generation immunosuppressive agent for organ transplantation, because it inhibits IL-2 translation and secretion and thus T-cell proliferation. In this context the cell autonomous $G_{1}$ arrest phenotype is augmented by inhibition of IL-2, which is a paracrine and autocrine growth factor for T cells. PEL are dependent on secreted autocrine growth factors. This has been established for the B-cell survival factors hIL-6 and hIL-10 (Komanduri et al., 1996; Asou et al., 1998; Aoki and Tosato, 1999; Drexler et al., 1999; Foussat et al., 1999; Jones et al., 1999; Chatterjee et al., 2002). IL-6, IL-10, IFNgamma, and IL12p40 secretion is inhibited by rapamycin (Sin et al., 2007). Other cytokines [IL- $1 \alpha$, IL-1 $\beta$, IL-2, IL-3, IL-4, IL-5, IL-7, IL-8, IL-12(p70), IL-13, IL-15, IP-10, Eotaxin, IFN $\gamma$, GM-CSF, MCP-1, MIP-1 $\alpha$, RANTES, and TNF $\alpha$ ] are not affected. VEGF-1 secretion is also inhibited by rapamycin (Damania, Dittmer, unpublished).

Clinically, both direct and indirect mechanisms may contribute to these responses. On one hand, tumor regression coincided with the recovery of T-cell memory responses against $\mathrm{KSHV}$ latent (Orf73) and lytic (K8.1) antigens (Barozzi et al., 2008). On the other hand, rapamycin is directly toxic to KSHV-infected cells (Sin et al., 2007), and KSHV-associated tumors, i.e., KS and PEL, depend on the mTOR signaling pathway, which is directly targeted by rapamycin (Sodhi et al., 2006; Wang and Damania, 2008). KS lesions almost universally exhibit phosphorylated Akt, which activates mTOR kinase and phosphorylated S6, which is a biomarker for mTOR kinase activity (Roy and Dittmer, 2011). This is expected since the PI3K/Akt pathway is activated upon of VEGFVEGFR stimulation in endothelial cells and by the activation of the B-cell receptor (BCR) complex in B cells.

Active Akt kinase promotes multiple cellular survival mechanisms: (i) Akt enhances protein synthesis through increasing the phosphorylation of mTOR (Gingras et al., 1998), (ii) Akt counteracts apoptosis by directly phosphorylating and inactivating pro-apoptotic factors such as BAD (Datta et al., 1997; Del Peso et al., 1997; Cardone et al., 1998), (iii) Akt phosphorylates a family of transcription factors known as the forkhead (FKHR) or FOXO 
transcription factors; Brunet et al., 1999; Kops and Burgering, 1999; Tang et al., 1999). Members of this family include FKHR (FOXO1a), FKHRL1 (FOXO3), and AFX (FOXO4). The net result of phosphorylation of the downstream targets of Akt is cell survival via inactivation of the FKHR family, GSK-3b, Caspase-9, and Bad (Cross et al., 1995; Datta et al., 1997; Del Peso et al., 1997; Cardone et al., 1998). Rapamycin blocks focus formation induced by oncogenic alleles of the upstream mTOR regulators, PI3K, or Akt (Aoki et al., 2001). Prolonged rapamycin treatment has been shown to lead to increased Akt phosphorylation by the mTOR-Rictor complex (Sarbassov et al., 2005, 2006), though this was not seen in KS. Thus, the efficacy of rapamycin (and more modern rapamycin analogs) in KS may plausibly be the result of a slightly different wiring of the PI3K/Akt/mTOR pathway in KSHV-associated cancers.

\section{PRIMARY EFFUSION LYMPHOMA}

The discovery of KSHV in KS prompted a frantic search for other cancers that may be associated with this new virus. Following the paradigm of EBV, which is seen in nasopharyngeal carcinoma, a solid organ cancer, as well as in lymphomas, KSHV sequences were rapidly identified in an uncommon type of B-cell lymphoma (Cesarman et al., 1995): PEL. KSHV infection is necessary for PEL development. The first cell lines for this lymphoma were obtained from body cavity effusions of what was hitherto called AIDS-associated lymphohematopoietic neoplasms. They carried EBV as well as KSHV (Knowles et al., 1989; Cesarman et al., 1995). PEL occurs with increased frequency in HIV-infected individuals; including those with concurrent KS. PEL account for $3 \%$ of AIDS-related lymphomas. This may be a skewed estimate, since it is may be quite common that AIDS patients die of other complications, including KS, before a diagnosis of PEL can be made (Nador et al., 1996; Gaidano et al., 1998). PEL is exceedingly rare in HIV-negative individuals (Walts et al., 1990; Green et al., 1995). The recognition that KSHV was always found in PEL, and EBV in 50-80\% of PEL, led to their classification as a new sub-type of non-Hodgkin lymphoma (Nador et al., 1996). PEL cell lines contain many copies of the KSHV genome as nuclear plasmids, which greatly facilitates molecular studies for this virus.

Primary effusion lymphoma can also occur in unusual sites (Said et al., 1996; Moatamed et al., 2011) and solid variants have been described as well. These variants also carry the KSHV genome and express at least the KSHV latent genes (Nador et al., 1996; Said et al., 1996; Engels et al., 2003; Chadburn et al., 2004; Carbone et al., 2005; Deloose et al., 2005). The diagnostic criteria for PEL (Nador et al., 1996; Cesarman and Knowles, 1999; Raphaël et al., 2008) include immunoblastic-anaplastic large-cell morphology, null-cell phenotype with no B-cell-associated antigen and immunoglobulin expression, and B-cell genotype as ascertained by BCR rearrangement. High CD138/Syndecan-1 (Gaidano et al., 1997) expression and hypermutation of immunoglobulin genes (Matolcsy et al., 1998) established that PELs are post-germinal center (GC) tumors at a pre-terminal stage prior to plasma-cell differentiation (this does not exclude the possibility that PEL arrived at this stage through extra-GC maturation). Transcript profiling confirmed this genesis (Palarcik, 1991; Jenner et al., 2003; Klein et al., 2003; O'Hara et al., 2008, 2009).
Survival on conventional chemotherapy is very poor (Nador et al., 1996; Simonelli et al., 2003), but of course PEL patients tend to have multiple comorbidities at presentation. The effusions may be managed by repeated drainage but eventually solid nests of PEL abolish vital organ functions. In PEL the p53 and PTEN genes are rarely mutated. P53 mutations accumulate after chemotherapy (Petre et al., 2007; Chen et al., 2010). FHIT and WWOX, two fragile site tumor suppressor genes, are deleted in many PEL cell lines (Roy et al., 2011), however these and other genome-wide association studies are limited by the scarcity of cases. Individual case reports document responses to anti-viral therapy, bortezomib, rapamycin (Sin et al., 2007), rituximab-containing chemotherapy regimens (Oksenhendler et al., 1998; Boulanger et al., 2001; Hocqueloux et al., 2001; Ghosh et al., 2003; Lim et al., 2005; Siddiqi and Joyce, 2008), or pleurodesis with bleomycin (Yiakoumis et al., 2011). Bortezomib's (Velcade ${ }^{\mathrm{TM}}$ ) primary mechanism of action is inhibition of the $26 \mathrm{~S}$ proteasome and nuclear factor $\mathrm{B}$ $(\mathrm{NF \kappa B})$ activity. Rapamycin (Sirolimus ${ }^{\mathrm{TM}}$ ) inhibits mTOR signaling, rituximab ( Rituxan $^{\mathrm{TM}}$ ) is a humanized monoclonal antibody against CD20, and bleomycin induces DNA breaks and eventually apoptosis in rapidly growing cells.

\section{MULTICENTRIC CASTLEMAN DISEASE}

One other disease entity has been convincingly associated with KSHV. This is a sub-type of Castleman disease, specifically the plasma-cell type (Keller et al., 1972). Castleman disease can be localized to just one, or multiple lymph nodes can be involved. The latter presentation is called MCD. MCD has mostly a plasmacell type morphology and is accompanied by systemic symptoms (Waterston and Bower, 2004). These systemic symptoms may be a result of cytokines, and in particular interleukin-6 (IL-6). The viral homolog, vIL-6 is expressed in scattered plasmablasts surrounding the lymphoid follicles in MCD (Berti et al., 1997; Cannon et al., 1999; Staskus et al., 1999). Thus, both KSHV-induced human IL-6 and virus-encoded vIL-6 are found at high levels in MCD. Recently, cases of an inflammatory syndrome with clinical symptoms similar to MCD have been described in AIDS patients with KS, but no diagnosis of MCD (Uldrick et al., 2010). Here too, high amounts of vIL- 6 in the serum have been noted. This suggests excess cytokine production is one of the systemic features of MCD (Hasson, 1985).

Multicentric Castleman disease patients may also develop concurrent frank cancer, such as KS and NHL. KSHV is invariably present in AIDS-associated MCD (Soulier et al., 1995; Larroche et al., 2002) and the presence of KS and MCD in the same lymph node is not rare. In some cases high angiosclerosis, GC, and perifollicular vascular proliferation is seen, while plasmacytosis was less pronounced (Suda et al., 2001). Studies are ongoing to better understand this disease and to arrive at a more succinct clinical description. The KSHV-positive cases may represent a distinct morphologic variant from KSHV-negative MCD (Dupin et al., 2000; Brousset et al., 2001). MCD lymph nodes can contain multiple KSHV-infected B cells, which may form microlymphomas or even frank lymphomas. Here, KSHV-infected plasmablasts are B-monotypic but polyclonal. They almost invariably express IgM-lambda (Du et al., 2001). The infected B-lineage plasmablasts in MCD differ from PEL. They lack somatic hypermutation and 
expression of CD138. They express cytoplasmic Ig and may also express CD27 (Du et al., 2001; Chadburn et al., 2008).

Median survival of MCD in HIV-positive individuals in the pre-ART era was approximately 14 months (Oksenhendler et al., 1996; Bower, 2010). Evidence of KSHV lytic viral protein expression led to testing of ganciclovir, with mixed results in small case series (Corbellino et al., 2001; Casper et al., 2004). This is not unexpected if for instance vIL-6 expression is independent, rather than coincident with viral lytic gene expression (Chatterjee et al., 2002). Under such a scenario the viral kinases orf36 and tk, which are required for ganciclovir efficacy would not be expressed. Alternatively, the drug regimen of just one anti-viral may be insufficient as a two-drug regimen combining valganciclovir and zidovudine (AZT), showed promising results (Uldrick et al., 2011).

In MCD rational therapy has shown remarkable responses. Treatment with tocilizumab, an anti-human interleukin-6 (IL-6) receptor monoclonal antibody, resulted in clinical responses in MCD patients that did not have AIDS (Nishimoto et al., 2005; Song et al., 2010); and the anti-CD20 antibody, rituximab, has shown responses in up to $70 \%$ of patients (Corbellino et al., 2001; Gerard et al., 2007; Bestawros et al., 2008; Bower, 2010; Bower et al., 2011). The mechanism here is not clear. In MCD, the KSHV-positive B cells frequently lack expression of CD20 (Chadburn et al., 2008; Naresh et al., 2009), so the source of systemic symptoms may be virus-negative plasma cells or other immune cells that respond to infection.

\section{REFERENCES}

Abada, R., Dreyfuss-Grossman, T., Herman-Bachinsky, Y., Geva, H., Masa, S. R., and Sarid, R. (2008). SIAH-1 interacts with the Kaposi's sarcoma-associated herpesvirusencoded ORF45 protein and promotes its ubiquitylation and proteasomal degradation. J. Virol. 82, 2230-2240.

Aoki, M., Blazek, E., and Vogt, P. K. (2001). A role of the kinase mTOR in cellular transformation induced by the oncoproteins $\mathrm{P} 3 \mathrm{k}$ and Akt. Proc. Natl. Acad. Sci. U.S.A. 98, 136-141.

Aoki, Y., and Tosato, G. (1999). Role of vascular endothelial growth factor/ vascular permeability factor in the pathogenesis of Kaposi's sarcomaassociated herpesvirus-infected primary effusion lymphomas. Blood 94 , 4247-4254.

Asou, H., Said, J. W., Yang, R., Munker, R., Park, D. J., Kamada, N., and Koeffler, H. P. (1998). Mechanisms of growth control of Kaposi's sarcomaassociated herpes virus-associated primary effusion lymphoma cells. Blood 91, 2475-2481.

Barozzi, P., Bonini, C., Potenza, L., Masetti, M., Cappelli, G., Gruarin, P., Whitby, D., Gerunda, G. E., Mondino, A., Riva, G., Vallerini, D., Quadrelli, C., Bosco, R., Ciceri, F., Bordignon, C., Schulz, T. F., Torelli,

\section{CHALLENGES}

Antiretroviral therapy has increased the life expectancy of the HIV-infected population. However, as these individuals age, there is likely to be a corresponding increase in the incidence of cancers in the HIV-positive population. Most of the current therapies do not target the unique viral etiology of cancers linked to KSHV infection. One exception are the antiherpes viral drugs which target lytic virus but do are not effective against latent virus. The interactions of chemotherapy with HIV protease inhibitors is also another consideration that needs to be addressed. In the future, it will be important to determine whether traditional chemotherapies are safe in the context of currently prescribed HIV protease inhibitors, and to devise newer therapies that directly target the viral etiology of these cancers.

\section{ACKNOWLEDGMENTS}

This work was supported by the University Cancer Research fund (UCRF) and NIH grants CA096500 and CA163217 to Blossom Damania, DE018304 to Dirk P. Dittmer and a translational award from the Leukemia and Lymphoma Society to Dirk P. Dittmer. Blossom Damania is a Leukemia and Lymphoma Society Scholar and a Burroughs Wellcome Fund Investigator in Infectious Disease. Kristy L. Richards is supported by an American Cancer Society Mentored Research Scholar Grant in Applied and Clinical Research.

primary effusion lymphoma in HIVinfected patients. Hematol. J. 2, 172-179.

Bower, M. (2010). How I treat HIVassociated multicentric Castleman disease. Blood 116, 4415-4421.

Bower, M., Nelson, M., Young, A. M., Thirlwell, C., Newsom-Davis, T. Mandalia, S., Dhillon, T., Holmes, P., Gazzard, B. G., and Stebbing, J. (2005). Immune reconstitution inflammatory syndrome associated with Kaposi's sarcoma. J. Clin. Oncol. 23, 5224-5228.

Bower, M., Newsom-Davis, T., Naresh, K., Merchant, S., Lee, B., Gazzard, B. Stebbing, J., and Nelson, M. (2011). Clinical features and outcome in $\mathrm{HIV}$-associated multicentric Castleman's disease. J. Clin. Oncol. 29, 2481-2486.

Bower, M., Palmieri, C., and Dhillon, T. (2006). AIDS-related malignancies: changing epidemiology and the impact of highly active antiretroviral therapy. Curr. Opin. Infect. Dis. 19, 14-19.

Brousset, P., Cesarman, E., Meggetto, F., Lamant, L., and Delsol, G. (2001). Colocalization of the viral interleukin-6 with latent nuclear antigen- 1 of human herpesvirus- 8 in endothelial spindle cells of Kaposi's sarcoma and lymphoid cells of multicentric Castleman's disease. Hum. Pathol. 32, 95-100.
Brunet, A., Bonni, A., Zigmond, M. J., Lin, M. Z., Juo, P., Hu, L. S., Anderson, M. J., Arden, K. C., Blenis, J., and Greenberg, M. E. (1999). Akt promotes cell survival by phosphorylating and inhibiting a Forkhead transcription factor. Cell 96, 857-868.

Campistol, J. M., Gutierrez-Dalmau, A., and Torregrosa, J. V. (2004). Conversion to sirolimus: a successful treatment for posttransplantation Kaposi's sarcoma. Transplantation 77, 760-762.

Cannon, J. S., Nicholas, J., Orenstein, J. M., Mann, R. B., Murray, P. G., Browning, P. J., Digiuseppe, J. A., Cesarman, E., Hayward, G. S., and Ambinder, R. F. (1999). Heterogeneity of viral IL-6 expression in HHV8-associated diseases. J. Infect. Dis. 180, 824-828.

Carbone, A., Gloghini, A., Vaccher, E., Cerri, M., Gaidano, G., DallaFavera, R., and Tirelli, U. (2005). Kaposi's sarcoma-associated herpesvirus/human herpesvirus type 8positive solid lymphomas: a tissuebased variant of primary effusion lymphoma. J. Mol. Diagn. 7, 17-27. Cardone, M. H., Roy, N., Stennicke, H. R., Salvesen, G. S., Franke, T. F., Stanbridge, E., Frisch, S., and Reed, J. C. (1998). Regulation of cell death protease caspase- 9 by phosphorylation. Science 282, 1318-1321. 
Casper, C., Nichols, W. G., Huang, M. L., Corey, L., and Wald, A. (2004). Remission of HHV-8 and HIVassociated multicentric Castleman disease with ganciclovir treatment. Blood 103, 1632-1634.

Cesarman, E., Chang, Y., Moore, P. S., Said, J. W., and Knowles, D. M. (1995). Kaposi's sarcoma-associated herpesvirus-like DNA sequences in AIDS-related body-cavity-based lymphomas. N. Engl. J. Med. 332, 1186-1191.

Cesarman, E., and Knowles, D. M. (1999). The role of Kaposi's sarcoma-associated herpesvirus (KSHV/HHV-8) in lymphoproliferative diseases. Semin. Cancer Biol. 9 , 165-174.

Chadburn, A., Hyjek, E., Mathew, S., Cesarman, E., Said, J., and Knowles, D. M. (2004). KSHV-positive solid lymphomas represent an extracavitary variant of primary effusion lymphoma. Am. J. Surg. Pathol. 28, 1401-1416.

Chadburn, A., Hyjek, E. M., Tam, W., Liu, Y., Rengifo, T., Cesarman, E., and Knowles, D. M. (2008). Immunophenotypic analysis of the Kaposi sarcoma herpesvirus (KSHV; HHV-8)-infected B cells in HIV+ multicentric Castleman disease (MCD). Histopathology 53, 513-524.

Chatterjee, M., Osborne, J., Bestetti, G., Chang, Y., and Moore, P. S. (2002). Viral IL-6-induced cell proliferation and immune evasion of interferon activity. Science 298, 1432-1435.

Chen, W., Hilton, I. B., Staudt, M. R., Burd, C. E., and Dittmer, D. P. (2010). Distinct p53,p53:LANA, and LANA complexes in Kaposi's sarcoma - associated herpesvirus lymphomas. J. Virol. 84, 3898-3908.

Cheung, M. C., Pantanowitz, L., and Dezube, B. J. (2005). AIDS-related malignancies: emerging challenges in the era of highly active antiretroviral therapy. Oncologist 10, 412-426.

Connick, E., Kane, M. A., White, I. E., Ryder, J., and Campbell, T. B. (2004). Immune reconstitution inflammatory syndrome associated with Kaposi sarcoma during potent antiretroviral therapy. Clin. Infect. Dis. 39, 1852-1855.

Corbellino, M., Bestetti, G., Scalamogna, C., Calattini, S., Galazzi, M., Meroni, L., Manganaro, D., Fasan, M., Moroni, M., Galli, M., and Parravicini, C. (2001). Longterm remission of Kaposi sarcomaassociated herpesvirus-related multicentric Castleman disease with anti-CD20 monoclonal antibody therapy. Blood 98, 3473-3475.
Crane, H. M., Deubner, H., Huang, J. C., Swanson, P. E., and Harrington, R. D. (2005). Fatal Kaposi's sarcomaassociated immune reconstitution following HAART initiation. Int. J. STD AIDS 16, 80-83.

Cross, D. A., Alessi, D. R., Cohen, P., Andjelkovich, M., and Hemmings, B. A. (1995). Inhibition of glycogen synthase kinase- 3 by insulin mediated by protein kinase B. Nature 378 , 785-789.

Datta, S. R., Dudek, H., Tao, X., Masters, S., Fu, H., Gotoh, Y., and Greenberg, M. E. (1997). Akt phosphorylation of BAD couples survival signals to the cell- intrinsic death machinery. Cell 91, 231-241.

Del Peso, L., Gonzalez-Garcia, M., Page, C., Herrera, R., and Nunez, G. (1997). Interleukin-3-induced phosphorylation of BAD through the protein kinase Akt. Science 278, 687-689.

Deloose, S. T., Smit, L. A., Pals, F. T., Kersten, M. J., Van Noesel, C. J., and Pals, S. T. (2005). High incidence of Kaposi sarcoma-associated herpesvirus infection in HIV-related solid immunoblastic/plasmablastic diffuse large B-cell lymphoma. Leukemia 19, 851-855.

Drexler, H. G., Meyer, C., Gaidano, G., and Carbone, A. (1999). Constitutive cytokine production by primary effusion (body cavitybased) lymphoma-derived cell lines. Leukemia 13, 634-640.

Du, M. Q., Liu, H., Diss, T. C., Ye, H., Hamoudi, R. A., Dupin, N., Meignin, V., Oksenhendler, E., Boshoff, C., and Isaacson, P. G. (2001). Kaposi sarcoma-associated herpesvirus infects monotypic (IgM lambda) but polyclonal naive B cells in Castleman disease and associated lymphoproliferative disorders. Blood 97, 2130-2136.

Dupin, N., Diss, T. L., Kellam, P., Tulliez, M., Du, M. Q., Sicard, D., Weiss, R. A., Isaacson, P. G., and Boshoff, C. (2000). HHV-8 is associated with a plasmablastic variant of Castleman disease that is linked to HHV8-positive plasmablastic lymphoma. Blood 95, 1406-1412.

Engels, E. A., Pittaluga, S., Whitby, D., Rabkin, C., Aoki, Y., Jaffe, E. S., and Goedert, J. J. (2003). Immunoblastic lymphoma in persons with AIDSassociated Kaposi's sarcoma: a role for Kaposi's sarcoma-associated herpesvirus. Mod. Pathol. 16, 424-429.

Foussat, A., Wijdenes, J., Bouchet, L., Gaidano, G., Neipel, F., Balabanian, K., Galanaud, P., Couderc, J., and Emilie, D. (1999). Human interleukin-6 is in vivo an autocrine growth factor for human herpesvirus-8-infected malignant $\mathrm{B}$ lymphocytes. Eur. Cytokine Netw. 10, 501-508.

Gaidano, G., Carbone, A., and DallaFavera, R. (1998). Pathogenesis of AIDS-related lymphomas: molecular and histogenetic heterogeneity. Am. J. Pathol. 152, 623-630.

Gaidano, G., Gloghini, A., Gattei, V., Rossi, M. F., Cilia, A. M., Godeas, C., Degan, M., Perin, T., Canzonieri, V., Aldinucci, D., Saglio, G., Carbone, A., and Pinto, A. (1997). Association of Kaposi's sarcoma-associated herpesvirus-positive primary effusion lymphoma with expression of the CD138/syndecan-1 antigen. Blood 90, 4894-4900.

Gantt, S., Carlsson, J., Ikoma, M. Gachelet, E., Gray, M., Geballe, A. P., Corey, L., Casper, C., Lagunoff, M., and Vieira, J. (2011). The HIV protease inhibitor nelfinavir inhibits Kaposi's sarcoma-associated herpesvirus replication in vitro. Antimicrob. Agents Chemother. 55, 2696-2703.

Gao, S. J., Kingsley, L., Hoover, D. R., Spira, T. J., Rinaldo, C. R., Saah, A., Phair, J., Detels, R., Parry, P., Chang, Y., and Moore, P. S. (1996a). Seroconversion to antibodies against Kaposi's sarcomaassociated herpesvirus-related latent nuclear antigens before the development of Kaposi's sarcoma. N. Engl. J. Med. 335, 233-241.

Gao, S. J., Kingsley, L., Li, M., Zheng, W. Parravicini, C., Ziegler, J., Newton, R., Rinaldo, C. R., Saah, A., Phair, J. Detels, R., Chang, Y., and Moore, P. S. (1996b). KSHV antibodies among Americans, Italians and Ugandans with and without Kaposi's sarcoma. Nat. Med. 2, 925-928.

Gerard, L., Berezne, A., Galicier, L., Meignin, V., Obadia, M., De Castro, N., Jacomet, C., Verdon, R., Madelaine-Chambrin, I. Boulanger, E., Chevret, S., Agbalika, F., and Oksenhendler, E. (2007). Prospective study of rituximab in chemotherapy-dependent human immunodeficiency virus associated multicentric Castleman's disease: ANRS 117 CastlemaB Trial. J. Clin. Oncol. 25, 3350-3356.

Ghosh, S. K., Wood, C., Boise, L. H., Mian, A. M., Deyev, V. V., Feuer, G., Toomey, N. L., Shank, N. C., Cabral, L., Barber, G. N., and Harrington, W. J. Jr. (2003). Potentiation of TRAIL-induced apoptosis in primary effusion lymphoma through azidothymidine-mediated inhibition of NF-kappa B. Blood 101, 2321-2327.
Gingras, A. C., Kennedy, S. G., O’leary, M. A., Sonenberg, N., and Hay, N. (1998). 4E-BP1, a repressor of mRNA translation, is phosphorylated and inactivated by the Akt(PKB) signaling pathway. Genes Dev. 12, 502-513.

Gottlieb, G. J., Ragaz, A., Vogel, J. V., Friedman-Kien, A., Rywlin, A. M., Weiner, E. A., and Ackerman, A. B. (1981). A preliminary communication on extensively disseminated Kaposi's sarcoma in young homosexual men. Am. J. Dermatopathol. 3, 111-114.

Green, I., Espiritu, E., Ladanyi, M., Chaponda, R., Wieczorek, R., Gallo, L., and Feiner, H. (1995). Primary lymphomatous effusions in AIDS a morphological, immunophenotypic, and molecular study. Mod. Pathol. 8, 39-45.

Guenova, E., Metzler, G., Hoetzenecker, W., Berneburg, M., and Rocken, M. (2008). Classic mediterranean Kaposi's sarcoma regression with sirolimus treatment. Arch. Dermatol. 144, 692-693.

Gutierrez-Dalmau, A., SanchezFructuoso, A., Sanz-Guajardo, A. Mazuecos, A., Franco, A., Rial, M. C., Iranzo, P., Torregrosa, J. V., Oppenheimer, F., and Campistol, J. M. (2005). Efficacy of conversion to sirolimus in posttransplantation Kaposi's sarcoma. Transplant. Proc. 37, 3836-3838.

Guttman-Yassky, E., Abada, R., KraOz, Z., Sattinger, J., Perelman, A. Bergman, R., and Sarid, R. (2007). Relationship between human herpesvirus 8 loads and disease stage in classic Kaposi sarcoma patients. Diagn. Microbiol. Infect. Dis. 57, 387-392.

Guttman-Yassky, E., Cohen, A., Kra$\mathrm{Oz}$, Z., Friedman-Birnbaum, R., Sprecher, E., Zaltzman, N., Friedman, E., Silbermann, M., Rubin, D., Linn, S., Whitby, D., Gideoni, O., Pollack, S., Bergman, R., and Sarid, R. (2004). Familial clustering of classic Kaposi sarcoma. J. Infect. Dis. 189, 2023-2026.

Harwood, A. R., Osoba, D., Hofstader, S. L., Goldstein, M. B., Cardella, C. J., Holecek, M. J., Kunynetz, R., and Giammarco, R. A. (1979). Kaposi's sarcoma in recipients of renal transplants. Am. J. Med. 67, 759-765.

Hasson, H. M. (1985). Open laparoscopy for tubal occlusion in the female. Adv. Contracept. 1, 181-189.

Hocqueloux, L., Agbalika, F., Oksenhendler, E., and Molina, J. M. (2001). Long-term remission of an AIDSrelated primary effusion lymphoma 
with antiviral therapy. AIDS 15, 280-282.

Jenner, R. G., Maillard, K., Cattini, N., Weiss, R. A., Boshoff, C., Wooster, R., and Kellam, P. (2003). Kaposi's sarcoma-associated herpesvirus-infected primary effusion lymphoma has a plasma cell gene expression profile. Proc. Natl. Acad. Sci. U.S.A. 100, 10399-10404.

Jones, K. D., Aoki, Y., Chang, Y., Moore, P. S., Yarchoan, R., and Tosato, G. (1999). Involvement of interleukin-10 (IL-10) and viral IL-6 in the spontaneous growth of Kaposi's sarcoma herpesvirusassociated infected primary effusion lymphoma cells. Blood 94, 2871-2879.

Kaposi, M. (1872). Idiopathisches multiples Pigmentsarkom der Haut. Arch. Dermatol. Syph. 4, 265-273.

Kedes, D. H., Operskalski, E., Busch, M., Kohn, R., Flood, J., and Ganem, D. (1996). The seroepidemiology of human herpesvirus 8 (Kaposi's sarcoma-associated herpesvirus): distribution of infection in KS risk groups and evidence for sexual transmission. Nat. Med. 2, 918-924.

Keller, A. R., Hochholzer, L., and Castleman, B. (1972). Hyaline-vascular and plasma-cell types of giant lymph node hyperplasia of the mediastinum and other locations. Cancer $29,670-683$

Klein, U., Gloghini, A., Gaidano, G., Chadburn, A., Cesarman, E., DallaFavera, R., and Carbone, A. (2003). Gene expression profile analysis of AIDS-related primary effusion lymphoma (PEL) suggests a plasmablastic derivation and identifies PEL-specific transcripts. Blood 101, 4115-4121.

Knowles, D. M., Inghirami, G., Ubriaco, A., and Dalla-Favera, R. (1989). Molecular genetic analysis of three AIDS-associated neoplasms of uncertain lineage demonstrates their B-cell derivation and the possible pathogenetic role of the Epstein-Barr virus. Blood 73, 792-799.

Komanduri, K. V., Luce, J. A., Mcgrath, M. S., Herndier, B. G., and $\mathrm{Ng}$, V. L. (1996). The natural history and molecular heterogeneity of HIV-associated primary malignant lymphomatous effusions. J. Acquir. Immune Defic. Syndr. Hum. Retrovirol. 13, 215-226.

Kops, G., and Burgering, B. (1999). Forkhead transcription factors: new insights into protein kinase B (cakt) signaling. J. Mol. Med. 77, 656-665.
Krown, S. E., Lee, J. Y., and Dittmer, D. P. (2008). More on HIV-associated Kaposi's sarcoma. N. Engl. J. Med. 358, 535-536.

Krown, S. E., Metroka, C., and Wernz, J. C. (1989). Kaposi's sarcoma in the acquired immune deficiency syndrome: a proposal for uniform evaluation, response, and staging criteria. AIDS Clinical Trials Group Oncology Committee. J. Clin. Oncol. 7, 1201-1207.

Krown, S. E., Roy, D., Lee, J. Y., Dezube, B. J., Reid, E. G., Venkataramanan, R., Han, K., Cesarman, E., and Dittmer, D. P. (2012). Rapamycin with antiretroviral therapy in AIDSassociated Kaposi sarcoma: an AIDS malignancy consortium study. $J$. Acquir. Immune Defic. Syndr. 59, 447-454.

Krown, S. E., Testa, M. A., and Huang, J. (1997). AIDS-related Kaposi's sarcoma: prospective validation of the AIDS Clinical Trials Group staging classification. AIDS Clinical Trials Group Oncology Committee. J. Clin. Oncol. 15, 3085-3092.

Larroche, C., Cacoub, P., Soulier, J., Oksenhendler, E., Clauvel, J. P., Piette, J. C., and Raphael, M. (2002). Castleman's disease and lymphoma: report of eight cases in HIV-negative patients and literature review. Am. J. Hematol. 69, 119-126.

Lebbe, C., Euvrard, S., Barrou, B., Pouteil-Noble, C., Garnier, J. L., Glotz, D., Legendre, C., and Frances, C. (2006). Sirolimus conversion for patients with posttransplant Kaposi's sarcoma. Am. J. Transplant. 6, 2164-2168.

Leidner, R. S., and Aboulafia, D. M. (2005). Recrudescent Kaposi's sarcoma after initiation of HAART: a manifestation of immune reconstitution syndrome. AIDS Patient Care STDS 19, 635-644.

Lim, S. T., Rubin, N., Said, J., and Levine, A. M. (2005). Primary effusion lymphoma: successful treatment with highly active antiretroviral therapy and rituximab. Ann. Hematol. 84, 551-552.

Maclean, C. M. (1963). Kaposi's sarcoma in Nigeria. Br. J. Cancer 17, 195-205.

Matolcsy, A., Nador, R. G., Cesarman, E., and Knowles, D. M. (1998). Immunoglobulin $\mathrm{VH}$ gene mutational analysis suggests that primary effusion lymphomas derive from different stages of B cell maturation. Am. J. Pathol. 153, 1609-1614.

Maurer, T., Ponte, M., and Leslie, K. (2007). HIV-associated Kaposi's sarcoma with a high CD4 count and a low viral load. N. Engl. J. Med. 357, 1352-1353.

Moatamed, N. A., Song, S. X., Apple, S. K., and Said, J. W. (2011). Primary effusion lymphoma involving the cerebrospinal fluid. Diagn. Cytopathol.

Monini, P., Sgadari, C., Toschi, E., Barillari, G., and Ensoli, B. (2004). Antitumour effects of antiretroviral therapy. Nat. Rev. Cancer 4, 861-875.

Myskowski, P. L., Niedzwiecki, D., Shurgot, B. A., Kaufman, D., Krown, S. E., Nisce, L., and Safai, B. (1988). AIDS-associated Kaposi's sarcoma: variables associated with survival. $J$. Am. Acad. Dermatol. 18, 1299-1306.

Nador, R. G., Cesarman, E., Chadburn, A., Dawson, D. B., Ansari, M. Q. Sald, J., and Knowles, D. M. (1996). Primary effusion lymphoma: a distinct clinicopathologic entity associated with the Kaposi's sarcomaassociated herpes virus. Blood 88 645-656.

Naresh, K. N., Trivedi, P., Horncastle, D., and Bower, M. (2009). CD20 expression in the HHV-8infected lymphoid cells in multicentric Castleman disease. Histopathology $55,358-359$.

Nasti, G., Talamini, R., Antinori, A., Martellotta, F., Jacchetti, G., Chiodo, F., Ballardini, G., Stoppini, L., Di Perri, G., Mena, M., Tavio, M., Vaccher, E., D’arminio Monforte, A., and Tirelli, U. (2003). AIDSrelated Kaposi's sarcoma: evaluation of potential new prognostic factors and assessment of the AIDS Clinical Trial Group Staging System in the Haart Era - the Italian Cooperative Group on AIDS and Tumors and the Italian Cohort of Patients Naive From Antiretrovirals. J. Clin. Oncol. 21, 2876-2882.

Nguyen, H. Q., Magaret, A. S., Kitahata, M. M., Van Rompaey, S. E., Wald, A., and Casper, C. (2008). Persistent Kaposi sarcoma in the era of highly active antiretroviral therapy: characterizing the predictors of clinical response. AIDS 22, 937-945.

Nishimoto, N., Kanakura, Y., Aozasa, K., Johkoh, T., Nakamura, M., Nakano, S., Nakano, N., Ikeda, Y., Sasaki, T., Nishioka, K., Hara, M., Taguchi, H., Kimura, Y., Kato, Y., Asaoku, H., Kumagai, S., Kodama, F., Nakahara, H., Hagihara, K., Yoshizaki, K., and Kishimoto, T. (2005). Humanized anti-interleukin-6 receptor antibody treatment of multicentric Castleman disease. Blood 106, 2627-2632.

O'Hara, A. J., Vahrson, W., and Dittmer, D. P. (2008). Gene alteration and precursor and mature microRNA transcription changes contribute to the miRNA signature of primary effusion lymphoma. Blood 111, 2347-2353.

O'Hara, A. J., Wang, L., Dezube, B. J., Harrington, W. J. Jr., Damania, B., and Dittmer, D. P. (2009). Tumor suppressor microRNAs are underrepresented in primary effusion lymphoma and Kaposi sarcoma. Blood 113, 5938-5941.

Oksenhendler, E., Clauvel, J. P., Jouveshomme, S., Davi, F., and Mansour, G. (1998). Complete remission of a primary effusion lymphoma with antiretroviral therapy. Am. $J$. Hematol. 57, 266.

Oksenhendler, E., Duarte, M., Soulier, J., Cacoub, P., Welker, Y., Cadranel, J., Cazals-Hatem, D., Autran, B., Clauvel, J. P., and Raphael, M. (1996). Multicentric Castleman's disease in HIV infection: a clinical and pathological study of 20 patients. AIDS 10, 61-67.

Palarcik, J. (1991). Clavicular fractures (group of patients treated in the Traumatological Research Institute in 1986-1989). Czech. Med. 14, 184-190.

Petre, C. E., Sin, S. H., and Dittmer, D. P. (2007). Functional p53 signaling in Kaposi's sarcoma-associated herpesvirus lymphomas: implications for therapy. J. Virol. 81, 1912-1922.

Raphaël, M., Said, J., Borisch, B., Cesarman, E., and Harris, N. L. (2008). "Lymphomas associated with HIV infection," in WHO Classification of Tumours of Haematopoietic and Lymphoid Tissues, eds S. H. Swerdlow, E. Campo, N. L. Harris, E. S Jaffe, S. A. Pileri, H. Stein, and J. Thiele (Lyon: IARC Press), 340-342.

Roy, D., and Dittmer, D. P. (2011). Phosphatase and tensin homolog on chromosome 10 is phosphorylated in primary effusion lymphoma and Kaposi's sarcoma. Am. J. Pathol. 179, 2108-2119.

Roy, D., Sin, S. H., Damania, B., and Dittmer, D. P. (2011). Tumor suppressor genes FHIT and WWOX are deleted in primary effusion lymphoma (PEL) cell lines. Blood 118 e32-e39.

Sabers, C. J., Martin, M. M., Brunn, G. J., Williams, J. M., Dumont, F. J., Wiederrecht, G., and Abraham, R. T. (1995). Isolation of a protein target of the FKBP12-rapamycin complex in mammalian cells. J. Biol. Chem. 270, 815-822.

Said, J. W., Tasaka, T., Takeuchi, S., Asou, H., De Vos, S., Cesarman, E., Knowles, D. M., and Koeffler, H. P. (1996). Primary effusion lymphoma in women: report of two cases of Kaposi's 
sarcoma herpes virus-associated effusion-based lymphoma in human immunodeficiency virus-negative women. Blood 88, 3124-3128.

Sarbassov, D. D., Ali, S. M., Sengupta, S., Sheen, J. H., Hsu, P. P., Bagley, A. F., Markhard, A. L., and Sabatini, D. M. (2006). Prolonged rapamycin treatment inhibits mTORC2 assembly and Akt/PKB. Mol. Cell 22, 159-168.

Sarbassov, D. D., Guertin, D. A., Ali, S. M., and Sabatini, D. M. (2005). Phosphorylation and regulation of Akt/PKB by the rictor-mTOR complex. Science 307, 1098-1101.

Siddiqi, T., and Joyce, R. M. (2008). A case of HIV-negative primary effusion lymphoma treated with bortezomib, pegylated liposomal doxorubicin, and rituximab. Clin. Lymphoma Myeloma 8, 300-304.

Simonelli, C., Spina, M., Cinelli, R., Talamini, R., Tedeschi, R., Gloghini, A., Vaccher, E., Carbone, A., and Tirelli, U. (2003). Clinical features and outcome of primary effusion lymphoma in HIV-infected patients: a single-institution study. J. Clin. Oncol. 21, 3948-3954.

Sin, S. H., Roy, D., Wang, L., Staudt, M. R., Fakhari, F. D., Patel, D. D., Henry, D., Harrington, W. J. Jr., Damania, B. A., and Dittmer, D. P. (2007). Rapamycin is efficacious against primary effusion lymphoma (PEL) cell lines in vivo by inhibiting autocrine signaling. Blood 109, 2165-2173.

Slavin, G., Cameron, H. M., Forbes, C., and Mitchell, R. M. (1970). Kaposi's sarcoma in East African children: a report of 51 cases. J. Pathol. 100, 187-199.

Sobin, L. H., Gospodarowicz, M. K., and Wittekind, C. (eds). (2009). TNM Classification of Malignant Tumours, 7th Edn. Wiley-Blackwell.
Sodhi, A., Chaisuparat, R., Hu, J., Ramsdell, A. K., Manning, B. D., Sausville, E. A., Sawai, E. T., Molinolo, A., Gutkind, J. S., and Montaner, S. (2006). The TSC $2 / m$ TOR pathway drives endothelial cell transformation induced by the Kaposi's sarcoma-associated herpesvirus G protein-coupled receptor. Cancer Cell 10, 133-143.

Song, S. N., Tomosugi, N., Kawabata, H., Ishikawa, T., Nishikawa, T., and Yoshizaki, K. (2010). Downregulation of hepcidin resulting from long-term treatment with an anti-IL-6 receptor antibody (tocilizumab) improves anemia of inflammation in multicentric Castleman disease. Blood 116, 3627-3634.

Soulier, J., Grollet, L., Oksenhendler, E., Cacoub, P., Cazals-Hatem, D., Babinet, P., D'agay, M. F., Clauvel, J. P., Raphael, M., Degos, L., and Sigaux, F. (1995). Kaposi's sarcoma-associated herpesvirus-like DNA sequences in multicentric Castleman's disease. Blood 86, 1276-1280.

Stallone, G., Schena, A., Infante, B., Di Paolo, S., Loverre, A., Maggio, G., Ranieri, E., Gesualdo, L., Schena, F. P., and Grandaliano, G. (2005). Sirolimus for Kaposi's sarcoma in renal-transplant recipients. N. Engl. J. Med. 352, 1317-1323.

Staskus, K. A., Sun, R., Miller, G., Racz, P., Jaslowski, A., Metroka, C., Brett-Smith, H., and Haase, A. T. (1999). Cellular tropism and viral interleukin-6 expression distinguish human herpesvirus 8 involvement in Kaposi's sarcoma, primary effusion lymphoma, and multicentric Castleman's disease. J. Virol. 73, 4181-4187.

Suda, T., Katano, H., Delsol, G., Kakiuchi, C., Nakamura, T., Shiota, M.,
Sata, T., Higashihara, M., and Mori, S. (2001). HHV-8 infection status of AIDS-unrelated and AIDSassociated multicentric Castleman's disease. Pathol. Int. 51, 671-679.

Tang, E. D., Nunez, G., Barr, F. G., and Guan, K. L. (1999). Negative regulation of the forkhead transcription factor FKHR by Akt. J. Biol. Chem. 274, 16741-16746.

Uldrick, T. S., Polizzotto, M. N., Aleman, K., O’Mahony, D., Wyvill, K. M., Wang, V., Marshall, V., Pittaluga, S. Steinberg, S. M., Tosato, G., Whitby, D., Little, R. F., and Yarchoan, R. (2011). High-dose zidovudine plus valganciclovir for Kaposi sarcoma herpesvirus-associated multicentric Castleman disease: a pilot study of virus-activated cytotoxic therapy. Blood 117, 6977-6986.

Uldrick, T. S., Wang, V., O’Mahony, D. Aleman, K., Wyvill, K. M., Marshall, V., Steinberg, S. M., Pittaluga, S., Maric, I., Whitby, D., Tosato, G., Little, R. F., and Yarchoan, R. (2010). An interleukin-6-related systemic inflammatory syndrome in patients co-infected with Kaposi sarcomaassociated herpesvirus and HIV but without multicentric Castleman disease. Clin. Infect. Dis. 51, 350-358.

Walts, A. E., Shintaku, I. P., and Said, J. W. (1990). Diagnosis of malignant lymphoma in effusions from patients with AIDS by gene rearrangement. Am. J. Clin. Pathol. 94, 170-175.

Wang, L., and Damania, B. (2008). Kaposi's sarcoma-associated herpesvirus confers a survival advantage to endothelial cells. Cancer Res. 68 , 4640-4648.

Waterston, A., and Bower, M. (2004). Fifty years of multicentric Castleman's disease. Acta Oncol. 43, 698-704.
Yiakoumis, X., Pangalis, G. A., Kyrtsonis, M. C., Vassilakopoulos, T. P., Kontopidou, F. N., Kalpadakis, C., Korkolopoulou, P., Levidou, G., Androulaki, A., Siakantaris, M. P., Sachanas, S., and Andreopoulos, A. (2011). Primary effusion lymphoma in two HIV-negative patients successfully treated with pleurodesis as first-line therapy. Anticancer Res. 30, 271-276.

Zmonarski, S. C., Boratynska, M., Rabczynski, J., Kazimierczak, K. and Klinger, M. (2005). Regression of Kaposi's sarcoma in renal graft recipients after conversion to sirolimus treatment. Transplant. Proc. 37, 964-966.

Conflict of Interest Statement: The authors declare that the research was conducted in the absence of any commercial or financial relationships that could be construed as a potential conflict of interest.

Received: 21 January 2012; paper pending published: 03 February 2012; accepted: 25 March 2012; published online: 18 April 2012.

Citation: Dittmer DP, Richards KL and Damania B (2012) Treatment of Kaposi sarcoma-associated herpesvirusassociated cancers. Front. Microbio. 3:141. doi: 10.3389/fmicb.2012.00141

This article was submitted to Frontiers in Virology, a specialty of Frontiers in Microbiology.

Copyright (C) 2012 Dittmer, Richards and Damania. This is an open-access article distributed under the terms of the Creative Commons Attribution Non Commercial License, which permits noncommercial use, distribution, and reproduction in other forums, provided the original authors and source are credited. 